\title{
Factores pedagógicos que inciden en la reprobación, en voz de los estudiantes normalistas.
}

\author{
Campos Cabañas, Belinda \\ Benemérita Escuela Normal Veracruzana \\ “Enrique C. Rébsamen”, México \\ belicamcabs@gmail.com
}

Resumen - La investigación analiza los factores que inciden en la reprobación de los estudiantes, considerando factores pedagógicoacadémicos, socioeconómicos, fisiológicos y psicológicos, desde la perspectiva de los estudiantes. Por lo extenso de la investigación, y la relevancia de la información, éste artículo reporta lo referente a los factores pedagógicos. Las actitudes y los criterios de evaluación resultaron ser los de mayor influencia.

Palabras claves - Reprobación; Escuela Normal; Factores Pedagógicos;

Abstract - The reprobation, recurrent problem in the Degree in Physical Education of the Benemérita Escuela Normal Veracruzana "Enrique C. Rébsamen". The research analyzes the factors that affect students' disapproval, considering pedagogical-academic, socioeconomic, physiological and psychological factors, from the perspective of the students. For the length of the research, and the relevance of the information, this article reports on the pedagogical factors. Attitudes and evaluation criteria proved to be the most influential.

Keywords - Reprobation; Normal School; Pedagogical factors;

\section{INTRODUCCIÓN}

La política educativa en nuestro país, expone los temas primordiales de la educación pública, tanto en el Plan Nacional de Desarrollo (PND) como el Programa Sectorial de Educación (PSE), articulando objetivos y estrategias y líneas de acción. Uno de esos temas es la reprobación, cifras oficiales emitidas por la Secretaría de Educación Pública (SEP, 2018) referentes al Sistema Educativo Nacional del periodo 2017-2018 la reportan con el $1.0 \%$ para Educación Primaria, el $5.3 \%$ para Educación Secundaria y 
un $13.2 \%$ para Educación Media Superior. Si bien a lo largo de la administración que está por concluir se implementó dentro del PND, la estrategia "3.1.5 Disminuir el abandono escolar, mejorar la eficiencia terminal en cada nivel educativo y aumentar las tasas de transición entre un nivel y otro" (Gobierno de la República, 2013, p.124), la disminución en los porcentajes fue mínima. En lo referente a la Educación Superior, nivel en el que se encuentra contemplada la Educación Normal, los indicadores que se reportan son en relación al abandono escolar (no a la reprobación), con un porcentaje de $6.8 \%$ (SEP, 2018, p. 33).

Recientemente el Instituto Nacional de Evaluación Educativa (INEE) publicó un documento en el que describe a las escuelas normales del país, indagando sobre sus recursos, agentes, procesos, resultados y estructura, como resultados reportan el porcentaje de alumnos egresados y titulados de educación normal según rango de edad por tipo de sostenimiento y modalidad (2005-2006 a 2015-2016), lo que representa la eficiencia terminal, pero no se abordan los fenómenos relacionados al fracaso escolar, como lo son la reprobación, rezago y abandono, dando la impresión de que no existen (Medrano, Méndez, y Morales, 2017).

En la Benemérita Escuela Normal Veracruzana "Enrique C. Rébsamen" (BENVECR), el fenómeno de la reprobación representa una problemática recurrente, junto con la deserción o abandono por baja temporal o definitiva, presentes en todas las licenciaturas, los índices más elevados de reprobación se han presentado en la Licenciatura en Educación Física, incrementándose hasta 35\% (BENVECR, 2018, p. 41).

En la BENVECR no existen, en registros, trabajos de investigación relacionados con la reprobación, la información que se encuentra es cuantitativa como parte de los procesos de registro que el área de evaluación de cada licenciatura lleva a cabo.

Dada la importancia que reviste la reprobación como problemática en la Licenciatura en Educación Fí- 
sica, e infiriendo el origen multicausal se realizó una investigación para analizar los factores que inciden en la reprobación de los estudiantes, considerando los factores pedagógico-académicos, los socioeconómicos, los fisiológicos y psicológico, desde la perspectiva de los estudiantes (Nava, Rodríguez y Zambrano, 2007). Este trabajo, permitió conocer sus posibles causas, aportando elementos que promueven la reflexión en torno a las acciones remediales que conduzcan a disminuir el alto índice de reprobación. Dada la relevancia y extensión de la información obtenida, el presente artículo sólo abordará lo referente a los factores pedagógicos.

\section{ANTECEDENTES}

Las investigaciones realizadas con relación al fenómeno de la reprobación en nivel superior, han sufrido transformaciones y de ser simples registros cuantitativos, de factores causales, se han convertido en interesantes fuentes de información cualitativa, conformando el estado teórico del tema.
La tendencia entre los trabajos estableció una clasificación de factores asociados a la reprobación, relacionados con el alumno, con el docente y con la institución, (Gómez y Astin citados en Corral y Díaz, 2009). Otro estudio muestra que los motivos más importantes que ocasionan esta problemática es el desconocimiento del plan de estudios, las actitudes y el poco o nulo apoyo en métodos de estudio de los alumnos, principalmente (Ruiz, Romano y Valenzuela, 2006). Así mismo, Talavera, Noreña y Plazola (2006) encontraron que en los factores de reprobación inciden aquellos relacionados con "la organización del tiempo, la carencia de hábitos y técnicas de estudio adecuadas por parte del estudiante, así como de estrategias didácticas por parte de los docentes, que permitan una mejor comprensión de los contenidos temáticos y con ello hacer eficiente el proceso de enseñanza-aprendizaje" (p. 2).

Además de analizar la magnitud de la problemática de reprobación y sus causas, desde la perspectiva de los estudiantes, Nava, et al. (2007), indagaron el tipo y las ma- 
terias involucradas en la reprobación, siendo como principales causas, el trabajo, los problemas familiares $y$ dificultades con las asignaturas. A diferencia del estudio realizado por Corral y Díaz (2009) en donde las causas principales son atribuibles al factor institucional, las del curriculum-plan de estudios; la conducta de matriculación y permanencia en clases; la orientación para el estudiante; la preocupación de la universidad por el estudiante y por último el aspecto administrativo del currículo.

Otro estudio de factores sociodemográficos-económicos, académicos y personales de alumnos que han reprobado durante su formación universitaria, identifica que son los problemas económicos durante su estancia universitaria, la comprensión de las asignaturas disciplinares y el tipo de licenciatura, sus principales causantes, así mismo califica positivamente el apoyo de los profesores a través de las asesorías y tutorías (Martínez, Hernández, Carrillo, Romualdo y Hernández, 2013).
Domínguez, Sandoval, Cruz y Pulido (2014) establece en su investigación como causas de la reprobación, en primer lugar, los factores referentes a la institución relacionados a la administración del programa educativo y los programas de apoyo; posteriormente, a los factores académicos que tienen que ver con la formación docente de los profesores, las estrategias de enseñanza, parámetros de evaluación y los antecedentes escolares de los estudiantes y por último, los motivacionales y personales como el desinterés de los alumnos, la necesidad de trabajar, inasistencias, poca dedicación a los estudios y el temor hacia los profesores.

El estudio realizado por Saucedo, Herrera, Díaz, Bautista y Salinas (2014) establece que las causas de la reprobación fueron que no entendían las explicaciones del profesor, el desinterés por la materia, la metodología del profesor, la mala relación entre el grupo $y$, por último, la mala relación con el profesor. Ramírez y Gallur (2017), al comparar artículos con el tema de la reprobación en nivel superior en Iberoamérica, destacan 
entre los factores que inciden en la reprobación: el contexto social y familiar, relativos a la institución de educación superior, antecedentes de bachillerato, estrategias de aprendizaje, factores cognitivos, desinterés del estudiante y falta de orientación vocacional oportuna Identificando a su vez los factores que no inciden en la reprobación, la asistencia a programas de tutoría y nivel sociodemográfico.

En Silva, Rodríguez y Leyva citados en Hernández, Hernández y Flores (2018) refieren como causas de la reprobación a los problemas socioeconómicos-familiares; hábitos $y$ estrategias de estudio, conocimientos previos deficientes; relación con los docentes, conocimientos y metodología de los profesores, criterios de evaluación; falta de motivación, dificultades de concentración, depresión, vocación por la carrera. Recientemente, se reportaron como causas de reprobación los asociados con la práctica docente, estrategias de aprendizaje, falta de buenos hábitos de estudio, relación con los docentes, su metodología y sus criterios de evaluación (Hernández, et al., 2018).
Con todos los referentes aquí expuestos, no queda duda que la reprobación es un fenómeno originado por diversas causas y no solamente las atribuibles al estudiante. La bibliografía revisada hace mención de factores causales de la reprobación en la educación superior (económicos, familiares, académicos, institucionales, etc.). Dicha bibliografía dio sustentos importantes al presente trabajo, cuyo enfoque teórico-metodológico es de tipo interpretativo, con elementos del crítico, en el que se retoma la percepción, opinión y experiencia de estudiantes quienes están inmersos en la problemática de la reprobación escolar.

En la investigación extensa se analizan factores pedagógicoacadémicos, socioeconómicos, fisiológicos, psicológicos y pedagógico-académicos que inciden en la reprobación, pero para los fines de este artículo, sólo se abordarán los factores pedagógicos.

\section{PERSPECTIVA TEÓRICA}

Pérez y Sacristán citados en Corral y Díaz (2009) definen "la reprobación escolar como el resultado de 
un proceso que detiene, limita o no acredita el avance del alumno en su vida académica". (p.3) Lo anterior se presenta al interior del aula, espacio de interacción con el maestro inmersos en la cotidianeidad de la vida escolar permeada por lo curricular, lo personal de los involucrados en esa interacción.

Al respecto, Valdés, citado por Ruiz et al. (2010), menciona que reprobar significa estrictamente no haber cubierto los requisitos mínimos que académicamente deberían satisfacerse y, por lo tanto, no obtener tal reconocimiento.

En el glosario de Educación Superior publicado por a ANUIES-SEP citado por Domínguez et al., (2014) al definir el concepto reprobación establece que "es una decisión que toma un profesor o un jurado con respecto al trabajo escolar de un alumno, curso o examen, y por la cual no se le conceden los créditos correspondientes debiendo, en consecuencia, repetir el curso o el examen. Se presenta cuando la población escolar sujeta a un programa curricular no cumple los requisitos académicos exigidos en el plan de estudio y por tanto no están en condiciones escolares de ser promovidos al grado" (p. 28).

Cuando un estudiante reprueba, se le atribuye a él la responsabilidad de ese hecho, puesto que se considera que reprueba debido a un pobre rendimiento académico demostrado en el examen, asignatura o curso; en este sentido, el resultado de la aplicación de estos procedimientos generalmente termina en una calificación "aprobatoria", o en el peor de los casos, "reprobatoria".

Así, "reprobar", que en sentido estricto es no cumplir los criterios exigidos en una muy particular prueba o tarea, casi siempre tiene implicaciones desde el punto de vista de los evaluadores mucho más generales hacia el estudiante -que en la mayoría de los casos no son consecuencia lógica de este hecho- como ser incompetente o ignorante, es considerada irremediable. (Reyes, 2005, p.2)Factores pedagógicos.

Díaz Barriga, citado por Talavera et al., (2006), señala que en la reprobación, convergen conflictos en- 
tre exigencias de la sociedad y de la institución educativa, necesidades de enseñanza de determinados contenidos, por el desempeño del maestro y no sólo por requerimientos individuales y sociales de los propios alumnos, de ahí la importancia de lo referente a los factores de tipo exógenos, no inherentes al estudiante, en este caso los factores pedagógicos que son todos aquellos que se relacionan al docente. En esta investigación se revisan la formación docente, el dominio de contenidos, estrategias didácticas, actitudes y criterio de evaluación como factores que inciden en la reprobación (Hernández et al., 2018).

\section{FORMACIÓN DOCENTE}

El concepto formación docente alude a los conocimientos, habilidades, actitudes, comportamientos relacionados que quedan en evidencia en la práctica docente, es decir, en las actividades antes, durante las clases, el empleo de técnicas didácticas, la evaluación y motivación de los alumnos entre otros. (Salas, 2007)

\section{DOMINIO DE CONTENIDOS}

El dominio de los contenidos o dominio de la materia o asignatura, entendido como experiencia o conocimiento disciplinar, si bien se valora la experiencia y el conocimiento de la asignatura o materia, se incluyen, además, la forma en que es capaz de incorporarlos a la realidad cotidiana del estudiante con una finalidad práctica, es decir, que la información que el docente le proporcione al estudiante, sea consistente y congruente con la realidad profesional. Esto se puede observar cuando el maestro proporciona ejemplos apropiados y concretos citando además fuentes importantes y valiosas evidenciando un sustento teórico pertinente (Hernández, 2011).

\section{EsTRATEGIAS DIDÁCTICAS}

Este concepto hace alusión las formas de planificar, organizar y desarrollar las acciones propias del proceso de enseñanza-aprendizaje que se evidencian en la práctica docente incluyen la elección de las técnicas y métodos más apropiados para el tema a tratar, las actividades para los alumnos que les brindarán mejores experiencias de 
aprendizaje, los materiales o recursos didácticos y tecnológicos que se van a emplear, así como tareas que realizarán los estudiantes (Castillo y Cabrerizo, 2006).

\section{ActiTud}

En el ámbito educativo, la actitud es un componente del curriculum tanto de docentes como de los estudiantes, particularmente la de los maestros, se evidencia al igual durante la práctica docente. Hernández (2011) menciona las características de la práctica docente efectiva centradas en aspectos personales del maestro reconocidas y apreciadas por los estudiantes.

Un docente que se muestra empático, accesible al diálogo y a la crítica, es capaz de entablar relaciones humanas adecuadas con sus alumnos, favoreciendo la buena comunicación, el clima favorable para la clase, siempre respetando a los demás en sus derechos y posicionamientos, motivando a sus alumnos, siendo sensible a sus necesidades y brindándoles un trato igualitario.

\section{CRITERIO DE EVAluACióN}

El Criterio de Evaluación es un enunciado que expresa el tipo y grado de aprendizaje que se espera que hayan alcanzado los estudiantes en un momento determinado, respecto de algún aspecto en concreto de lo que indican los objetivos generales. La propuesta de evaluación que Estévez (2002) plantea que se debe evaluar lo que realmente se enseñó, es decir de acuerdo al curriculum real y no al formal, considerando los diferentes niveles y estilos de aprendizaje de los alumnos identificando el desarrollo cognitivo en el que se encuentran para establecer nuevas estrategias que reorienten la enseñanza considerando todos los ámbitos de aprendizaje y no solo conductas o rendimientos observables. En este tipo de evaluación se propone evaluar a todos los actores del proceso educativo, las características del profesor, los materiales de estudio, los recursos, las relaciones, espacios físicos, prácticas administrativas etcétera.

Tanto los factores los pedagógicos, aquí descritos, como las subcategorías que se consideraron, 
son un primer referente para futuras investigaciones, describiendo la interacción de docente y estudiantes en el fenómeno de la reprobación.

\section{MÉTODO}

La investigación que se realizó es un estudio descriptivo interpretativo con enfoque cualitativo, para estudiar una realidad social como lo es la reprobación, que se presenta al interior de la Licenciatura en Educación Física dando voz a sus actores, los estudiantes, quienes expresan las opiniones que tienen al respecto de las causas de la reprobación. La población seleccionada fueron los estudiantes del $6^{\circ}$ semestre que hubieran reprobado alguna asignatura a lo largo de su trayectoria escolar hasta el quinto semestre, se seleccionó por criterio intencionado, una muestra de 6 estudiantes con dos o más asignaturas reprobada en el transcurso de dos o más semestres con la experiencia de haber presentado exámenes con carácter de R1 y R2. Se les asignó la nomenclatura con doble letra $\mathrm{E}$ y número progresivo del 1 al 6 para su identificación (EE1, EE2, EE3, EE4, EE5 y EE6).
Como técnica de investigación se empleó la entrevista, para lo cual se elaboró el guion de entrevista semi-estructurada, en la cual se plantearon cuestionamientos referentes a las opiniones y experiencias respecto a las causas de la reprobación, divididos en cuatro apartados: factores pedagógicos, factores socioeconómicos, factores fisiológicos y factores psicológicos. Se contó con el uso de grabadora que permitió registrar todas las interacciones verbales que se produjeron entre entrevistadora $y$ entrevistado para, posteriormente proceder a la transcripción de cada una de las entrevistas resguardando debidamente todo el material informativo tanto el audio como el escrito en archivos electrónicos para la siguiente etapa de la investigación, el análisis de los resultados, para lo cual y con el propósito de agilizar el análisis, se identificaron con colores las categorías estaban en los registros, posteriormente se trabajó cada categoría, con sus respectivas subcategorías. 


\section{CONTEXTO}

La Benemérita Escuela Normal Veracruzana "Enrique C. Rébsamen", es una institución pública de educación superior, fundada en 1886, cuya misión sustancial es la formación inicial de docentes para la educación básica. Desde 1984 brinda estudios de nivel licenciatura, entre las diversas licenciaturas que se ofertan en la BENV se encuentra la Licenciatura en Educación Física que inició actividades en 1993 con el plan de estudios 1982; el cual, tenía un enfoque técnico deportivo, actualmente se opera con el plan de estudios 2002 en términos generales, marcó la pauta considerando ya los principios pedagógicos, los conocimientos y las habilidades a desarrollar en la formación de estudiantes así como los rasgos, las cualidades y las características del profesional en su perfil de egreso.

El personal docente que labora en la Licenciatura es de diversa formación profesional: hay psicólogos, abogados, licenciados en educación física, pedagogos entre otros perfiles; la plantilla docente está conformada por 56 maestros de los cuales 17 son mujeres y 39 hombres. Los estudiantes de la Licenciatura en Educación Física son jóvenes que provienen de diversas regiones del estado e incluso de otros estados de la República. Sus edades oscilan entre los 17 y 22 años en promedio. Hay tres grupos de primero, tres de segundo, tres de tercero y tres de cuarto dando un total de 301 alumnos inscritos, de los cuales 216 son hombres y 85 son mujeres.

\section{Resultados}

A continuación, se muestran los factores pedagógicos, desglosados en sub categorías.

\section{Subcategoría Formación do- cente.}

Ante la pregunta ¿Cuál era su formación docente y en qué medida contribuyó a que reprobaras? El alumno alude a la formación profesional (pero no a la formación docente) del maestro, asegurando que esto no influyó para que reprobara.

"El maestro es psicólogo, siento que no eso no tuvo nada que ver" (EE5). 
Otro caso considera que no influyó el maestro para que reprobara, sino que asume que fueron otros los motivos para reprobar:

"Eh, bueno hablando de las primeras asignaturas en el primer semestre que cuando reprobé parece que cuatro, no tuvo mucho que ver el maestro, más que nada fue que, pues venía de un proceso de ir reprobando y de no tomar muy en serio la carrera en sí y fue el factor que más influyó a que reprobara" (EE2).

De acuerdo a las opiniones de los estudiantes entrevistados, la formación docente carece de influencia en la reprobación.

Subcategoría Dominio de contenidos.

Ante la pregunta ¿el docente dominaba los contenidos de la asignatura? $Y$ si eso ¿Influyó eso en tu reprobación? El estudiante reconoce poco conocimiento de la asignatura por parte del docente si influye en la reprobación.

"A veces, tenía muy poco conocimiento de los temas siento que, quedan muy cortos en cierto sentido ciertas materias, no basta el conocimiento muchos de los maestros que tuve habia asignaturas que las estaban dando por primera vez y ellos mismos no sabian ni que era y este, eso influye ..." (EE1).

El alumno considera que hay algunos que, si los dominan y otros que no, hacen la crítica que por la falta de dominio las explicaciones no son suficientes reportando esto como causas para reprobar.

"Bueno, en sintesis, todos los maestros si tienen buen manejo a excepción de unos cuantos que sentí que falto, no sé, falto mayor explicación de los contenidos como que no logré llevarme nada de su asignatura en sí, y este, pues creo que, eso fue lo que más me orilló a que reprobara esa materia..." (EE2).

Otro estudiante afirma que el si había dominio de contenidos por que "si sabía", pero el docente no cumplía con las responsabilidades de su rol, considerando esto una causa para reprobar.

"En la de desarrollo de los adolescentes el maestro se ve que, si sabia, pero cuando llegaba a las clases pues no enseñaba nada que tuviera que ver con el tema ... eso influyo a que varios reprobáramos" (EE4). 
Otros casos, en los que sí reconoce que el docente domina los contenidos, pero igualmente haciendo alusión al uso de estrategias considera que el docente no es hábil para enseñar, aludiendo a los "excelentes maestros que ha tenido".

"En parte si, pues es el maestro debe de tenerlo, pero siento que no tenía la habilidad como para enseñar porque me han tocado otros maestros que tienen una habilidad excelente para ser maestro" (EE3).

Para los estudiantes, el dominio de los contenidos, es valorado, pero no lo consideran un factor que influya en la reprobación.

\section{Subcategoría Estrategias didácticas.}

Con respecto a la pregunta ¿Consideras que las estrategias didácticas que empleó el maestro pudieron influir para que reprobaras? el estudiante refiere que el docente sólo los ponía a leer, y a comentar ejemplos con poco fundamento teórico razón que contribuye a la reprobación.

“...nada más nos decía lean la lectura, al otro día llegábamos nada más se ponía a comentar a hacer, así como ejemplos nada más pero nunca nos decía este viene en tal, en tal y en tal, entonces en los exámenes nos ponía de toda la antología que no habíamos visto nada, habiamos visto puros ejemplos, entonces por éramos como 11 que reprobamos" (EE1).

Otro caso en el que se valora el esfuerzo del docente, pero no se abordaron los temas adecuadamente puesto que no hubo estrategia didáctica.

"Eh, en algunos casos creo que, si existió, pues el trabajo por parte del maestro, si trató, pero, no sé, creo que, así siguió sin abordar los puntos más importantes de lo que queríamos aprender y pues no logré pues captar algo buen o de la información” (EE2).

Existen estrategias que no favorecen el aprendizaje y que fueron recurrentes en las clases:

"Pues es que siempre nos ponia a leer a sacar puntos $y$ esos puntos entregárselos y yo varias veces bueno como ya es esto algo predecible, el maestro, luego de flojera, es esto, es más que nada la flojera de realizar la misma actividad pues todas las clases" (EE3). 
Algunos estudiantes son capaces de identificar que el docente carece de estrategia didáctica, y que el nivel de participación de los estudiantes al comentar ciertos textos se queda en el nivel de la anécdota y no a profundidad.

"Estrategias yo creo que no, la única que hacía era nada más comentarios decía algo y los demás comentábamos, pero no decía tal autor dice esto, que bien, este concepto viene aqui nada más comentaba acerca del título yo creo y veía y ya se la sabía, pero nosotros no entonces el comentaba el título y comenzábamos a decirle a mi hermano le pasa asi o tengo un primo que le pasó esto" (EE4).

\section{Y ante la pregunta expresa,} Crees que esa forma de trabajo influyó para que reprobaras, reconociendo éste aspecto como un factor que influye en la reprobación.

$$
\text { "Pues si en parte" (EE4). }
$$

Los estudiantes refieren que el docente recurría a la estrategia didáctica, de trabajar en equipos, exponiendo los temas y brindando un breve comentario no a profundidad que la temática requería.

"Que nos ponía por equipos a hacer exposiciones de la anto- logía ya cuando un equipo terminaba de exponer, explicaba los puntos que quedaban muy asi a la ligera" (EE5).

Algunos alumnos reconocen que hay maestros que si utilizan estrategia didáctica y que quien falló fueron ellos:

"La estrategia del profe $X$, si, la verdad si es muy buena, sus clases son muy buenas, pero yo no rendi" (EE6).

Para los estudiantes en su mayoría, consideran que las estrategias didácticas no influyen en la reprobación, directamente, pero si contribuye a el desinterés.

\section{Subcategoría Actitudes.}

Ante la pregunta ¿Cuáles eran las actitudes del profesor hacia el grupo y hacia ti y en qué forma esto contribuyó a que reprobaras?

El estudiante menciona que sí contribuye, aunque reconoce que requieren de acciones disciplinarias y de control, muestran rechazo por los docentes que los ejercen, se asume como indisciplinado, pero asegura que la disciplina es positiva. 
"Si, influyó, siempre he tenido problemas de conducta ajá, y sí, siempre influye la disciplina, es fundamental $y$, ciertamente, hay maestros que son muy estrictos y choco por lo mismo de que soy un poco indisciplinado y ellos necesitan mucha disciplina y hay mucho control y siempre he chocado con el control, mucho" (EE 1).

El estudiante valora los intentos del docente por conservar una buena relación, aunque de igual manera ha tenido dificultades con ella.

"Varios maestros como que trataban de tener una buena relación con nosotros, pero a veces como que no, por ejemplo, en particular con la Mtra. " $W$ " que luego tengo muchos problemas, entonces, ahorita en este semestre $y$ en el anterior que nos daba..." (EE2).

Una estudiante expone el incumplimiento de las reglas o los acuerdos establecidos en el grupo, por parte del docente, como la entrega de trabajos o la hora de entrar a la clase, genera molestia y desacuerdos.

“.. los reglamentos, las normas que se iban a seguir dentro del salón y por ejemplo, las fechas de entrega, y si no la entre- gas, de repente, surgía un problema y daba un espacio para que hubiera otro dia, o pues si llego yo a tal hora nadie más va a entrar $y$ de repente entraba otro y se rompia esa regla y así, siempre había esa discusión con ella y ese problema y hasta la fecha creo que siempre ha existido, nunca nos hemos puesto de acuerdo y es lo que a mi en lo particular si me molesta mucho, porque influyen a la reprobación..." (EE2).

Los estudiantes critican el hecho de que hay maestros que en ciertos momentos su actitud era muy relajada y en otros, con sus comentarios y acciones un tanto molestos provocaban el ausentismo de los estudiantes, y al no asistir les afecta en la reprobación por el número de faltas.

"de relajo era llevado, pero no se aguantaba y conmigo siempre me ponía en evidencia con los compañeros, con mi compañero que le comento y que se fue, a nosotros dos siempre nos decía ah, los compadres-porque habia veces que, si nos salíamos por lo mismo que nos aburría, pero si era muy como evidenciarnos frente al grupo y por las faltas muchas repruebas" (EE3). 
Los estudiantes mencionan que existen docentes con actitudes y comentarios mordaces en todo momento, aunque reconocen que eran comentarios dirigidos a estudiantes que no rendían en clase y que los molestada siempre, aunque consideran que parecían comentarios en tono de broma, pero no pueden asegurarlo:

"Echaba relajo, pero como que te amedrentaba, te molesta$b a$, porque a un compañero que casi no se le daba lo de la estudiada, todos los días decía-ya para que estás aquí, ya vete a Tamaulipas, ya presenta examen, no vas a pasar conmigo--- y hasta el momento siempre le dice lo mismo, asi a varios les dice--- ya mejor vete ya para que estás aquí en relajo no lo dice en serio, bueno ¿Quién sabe? pero él se ríe. En los exámenes también te decía $y$ como que te presiona, te dice-ya para que estudias" (EE4).

y así como los estudiantes critican el actuar del docente, también son capaces de reconocer a los maestros que muestran actitudes que favorecen el ambiente dentro del aula, como el respeto hacia los estudiantes:

"Siempre bien el maestro muy respetuoso hacia todos" (EE5).
¿Ante la pregunta expresa de que si la actitud del docente influyó en la reprobación?, los estudiantes aseguran que no, asumen que son otras las razones por las cuales ellos reprobaron, pero son capaces de reconocer los diversos estilos de docencia que permiten una cercanía mayor o menor con los estudiantes.

"Pues con el profe " $X$ " no influyó nada de hecho, él me motivaba, porque se daba cuenta que yo, cuando era de participar le ponía mucho empeño y siempre habia dias en que llegaba a las siete de la mañana y me dormía por ejemplo, porque llegaba cansado, me desvelaba asi alguna cosa y el profe " $X$ " me motivaba - No EE6, échale ganas-- y si de vez en cuando agarraba el paso pero otra vez lo perdía pues ahi influyó, el profe " $Y$ " en lo personal no hubo ahi esa como cohesión de alumno y maestro yo veo que con la otra generación que están arriba los que van a salir ahorita, platican más con él tienen una mejor interacción y con nosotros fue un poco más distante, digamos con todo el grupo, conmigo más y pues eso si me afecto" (EE6).

Los estudiantes entrevistados consideran que ciertas actitudes de los profesores son causas de repro- 
bación escolar, ya que influyen en el fomento de un ambiente poco propicio para el aprendizaje en el aula.

Criterio de evaluación.

En lo referente a la pregunta ¿EI criterio de evaluación afectó de alguna forma para que reprobara y en qué medida? Se menciona que, el criterio de evaluación afecta de tal manera en la reprobación por el valor que el docente les asigna a las faltas para evaluar al estudiante, además del porcentaje de inasistencias que asigna la Secretaría de escuela y que lo considera "doble", aunado a la no entrega de productos y/o trabajo:

"Claro, el criterio de evaluación del maestro pues como yo siento, mi punto de vista, que toman dos veces la asistencia, de por sí, en secretaría si no vienes tienes $R 2$, pero de acá también desde el salón que te toman en cuenta un punto o dos puntos y eso va bajando y las actividades y tareas que se llevan en el salón pues claro que llega el momento que, pues si no vienes o no tienes todo y repruebas, aunque en los exámenes salga alto no me alcanza el promedio por lo que se realiza" (EE1).
Con relación al criterio de evaluación, los estudiantes hacen la referencia a la exigencia de un elemento de la evaluación, al que se le daba mucha importancia, los exámenes con respuesta casi textual, citando al autor y exponen la dificultad de aprenderse todo como lo expone el autor, considerando que esto afectó su calificación. Lo anterior contrasta con el reconocimiento que hacen de la poca o casi nula exigencia de tareas.

"Pues de tareas que yo me acuerde, no encargaba muchas tareas lo que si que le daba más importancia era al examen, los exámenes regularmente eran asi de 30 y 40 preguntas y todas eran dirigidas a un apartado del texto citando en autor o algo asi y a veces era de completar la pregunta a veces abarcaba lo de tres cuatro renglones y tenías que abarcar una frase alguna sola cosa, que le digo, a veces no era muy fácil de aprendérsela y menos estudiar un párrafo de un texto quien iba a saber que párrafo iba a poner en si" (EE2).

Ante la pregunta expresa de que, si consideras que esa forma de evaluar afectó tu calificación en relación con lo anterior, ellos consideran que sí afecta: 
Factores pedagógicos que inciden en la reprobación, ...

"Pues sí, yo creo que sí, no te puedes aprender un concepto asi, más o menos te das una idea de cómo comprendiste y tenía que ser exactamente como decía el autor" (EE2).

La estudiante, expresa que el trato diferenciado de parte del docente hacia los estudiantes, en relación a la evaluación que genera molestia, y le reconoce que las actitudes influyen en la reprobación.

“...en las mismas evaluaciones, que, si tal acierto está bien para uno, para el otro no está bien y así eso llega a causar muchos problemas es lo que no me parece justo, incluso luego quiera uno entablar una conversación o ponerse de acuerdo y no se puede y como que no, porque si yo sé que cometí un error, pues ya, no hay problema, respondo por ello, pero si no hay igualdad para todos no se puede y si influye a la reprobación" (EE2).

También existen los estudiantes que reconocen que los criterios de evaluación se dan a conocer previamente, pero lo influye para reprobar es la no entrega de productos $y / 0$ trabajos solicitados por el docente, además de la no participación e indisciplina.
"Si lo manejó, el problema aqui fue que no entregué los trabajos que pidió eso mismo aunado a que echaba relajo o no participaba este pues yo creo contribuyó a que tuviera esa calificación" (EE3).

Los estudiantes refieren al docente que no establece al inicio del curso nada respecto al criterio de evaluación, que maneja los porcentajes sin consensar con los estudiantes esto definitivamente lo consideran un factor asociado a su reprobación.

"El maestro no dijo cómo iba a evaluar y cuando daba la calificación tampoco decía que sacamos tanto de examen ni nada, dijo que el examen valía $60 \%$ y lo demás nunca supimos, de hecho, decía que valía 10 pero ya cuando daba calificaciones nada más valía 8" (EE4).

También se encuentran los estudiantes que reconocen que sí se les informó el criterio de evaluación por parte del docente, y si consideran el criterio de evaluación como un factor que influye en la reprobación, pero critican el porcentaje que se le asigna al examen, y considerándolo excesivo. 
"las exposiciones y tareas valian un $40 \%$ pero a lo que le daba más valor era al examen un $60 \%$, si lo decía, si influyó en parte esa forma de evaluar yo hubiera propuesto no darle tanto valor al examen, que un 60\% si es algo, y disminuirle a 30 o 40", (EE5).

La diversidad de criterios de evaluación se pone de manifiesto cuando los estudiantes hacen un comparativo entre dos maestros exponiendo por supuesto, su preferencia por criterios que consideren trabajos y participación y no sólo el examen, ya que esto lo consideran una causa para su reprobación:

"Como le digo con el profe " $Y$ " el examen era altísimo el valor y pues muy complicado, a la mayoría, nos llevó a reprobar con el éramos muchos y con el profe " $X$ " era accesible la evaluación, habia trabajos, examen y participaciones y demás, entonces el ya juntaba. Con el maestro "Y "Solo con el examen con lo que sabes ya si no lo sabes no apruebas" (EE6).

Los estudiantes si les atribuyen a los criterios de evaluación, influencia en la reprobación, hacen una crítica al tipo de examen que la ma- yoría incluye, de respuesta textual con un porcentaje elevado para evaluación.

\section{CONCLUSIONES}

La formación docente no influye en la reprobación, según la percepción de los estudiantes, y lo que sí consideran como causa de reprobación es el desinterés por los cursos.

El dominio de contenidos representa poca importancia como causa de la reprobación, en comparación con las estrategias didácticas que mencionan reiteradamente como causal, así como la falta de interés que genera el ausentismo de los estudiantes; de igual manera, los estudiantes son capaces de reconocer quién los domina y quién no, incluso existe quien cataloga de excelente a algunos maestros que le han dado clases.

Con respecto a las estrategias didácticas, sólo un estudiante reportó considerarlas como una causa para reprobar, relacionan conocimiento de la asignatura con estrategia didáctica y si es poco el conocimiento, es poca o nula la estrategia, cuando si hay, la estrategia es poco innovadora generando 
aburrimiento y desinterés, o aún con estrategia, el contenido no se abordó adecuadamente de manera que los ejemplos para reforzarlos se quedan en simples anécdotas, los estudiantes reconocen que hay docentes que sí implementan estrategias didácticas y quienes fallan realmente son ellos.

La mayoría de los estudiantes considera que las actitudes sí influyen en la reprobación, sobre todo porque genera molestia y ausentismo de los estudiantes y por el número de inasistencias es que reprueban. Critican actitudes ya sea por excesiva disciplina o control o demasiada relajación o "relajo", falta de congruencia en el respeto a las reglas o acuerdos, criterios de evaluación diferenciados, comentarios incómodos, falta de cercanía con los alumnos, nula motivación.

Los estudiantes reconocen cuando se les informan en tiempo y forma los criterios de evaluación, pero que de igual forma a ambas situaciones le atribuyen influencia en la reprobación, así como el tipo de exámenes que se les aplica pudiendo ser muy extensos y que requieren respuestas textuales; reconocen que el no entregar trabajos también afecta en la reprobación criticando los porcentajes asignados al examen.

A través de este trabajo se tuvo un acercamiento con el fenómeno de la reprobación en voz de los estudiantes, sería interesante y necesario conocer cuáles son las opiniones de los docentes, para tener una visión amplia y más completa de la realidad, que permita emprender las acciones remediales pertinentes. Para los estudiantes, adquiriendo mayor conciencia del papel que representan en esta problemática, y mejorar su trayecto académico, para los docentes, reconocer lo positivo de sus prácticas, pero sobretodo lo negativo que requiere transformación para mejorar sus desempeños.

La institución a su vez deberá intervenir, reconociendo la presencia de la problemática, dando la atención adecuada al fenómeno de la reprobación, buscar entre los actores las mejores propuestas de solución de manera incluyente y no "fiscalizadora" en busca propiciar mejores ambientes de aprendizaje al interior de las aulas que favorez- 
can las actitudes y criterios de evaluación acordes con las exigencias de una educación de calidad y de calidez.

\section{REFERENCIAS}

BENVECR (2018) Plan de desarrollo institucional 2018-2023. Documento de trabajo sin publicar, Área de Planeación. Veracruz, México: Benemérita Escuela Normal Veracruzana "Enríque C. Rébsamen".

Corral, V. y Díaz, X. (2009) Factores asociados a la reprobación de los estudiantes de la Universidad de Sonora. Recuperado de: http://www.comie.org.mx/congreso/m emoriaelectronica/v10/pdf/area_tema tica_16/ponencias/0910-F.pdf

Domínguez, D., Sandoval, M., Cruz, F., y Pulido, A. (2014). Problemas relacionados con la eficiencia terminal desde la perspectiva de estudiantes universitarios. REICE. Revista Iberoamericana sobre Calidad, Eficacia y cambio en Educación, 12(1), 25-34. Recuperado de:

https://www.redalyc.org/articulo.oa?id $=55129541002$

\section{Esteves, E. (2002) Enseñar a} aprender. Estrategias Cognitivas. México: Paidós

Gobierno de la República (2013). Plan Nacional de Desarrollo (PND) 2013-2018. México. Recuperado de: http://pnd.gob.mx/

Hernández, G. (2011) Práctica Docente. Más allá de cuatro paredes, pizarrón y mesa bancos. México: Arana.

Hernández, E., Hernández, G., y Flores, A. (2018) La reprobación en una universidad del sureste de México: el caso de la Licenciatura en Humanidades. UNIVERSITA CIENCIA Revista electrónica de investigación de la Universidad de Xalapa, 6, (18). Recuperado de: https://docplayer.es/85752232-Lareprobacion-en-una-universidad-delsureste-de-mexico-el-caso-de-lalicenciatura-en-humanidades.html

Martínez, A., Hernández, L., Carrillo, D., Romualdo, Z., y Hernández C. (2013). Factores asociados a la reprobación estudiantil en la Universidad de la Sierra Sur, Oaxaca. Temas de Ciencia y Tecnología, 17(51), 25-33. Recuperado de: http://www.utm.mx/edi_anteriores/tem as51/T51_1Ensayo3FactAsocReprob acion.pdf

Medrano, V., Méndez, E., y Morales, M. (2017) La educación normal en México Elementos para su análisis: INEE. Recuperado de: https://www.inee.edu.mx/index.php/p ublicaciones-micrositio

Nava Bustos, G, Rodríguez Roldán, P. y Zambrano Guzmán, R. (2007) Factores de Factores de reprobación en los alumnos del Centro Universitario de Ciencias de la Salud de la Universidad de Guadalajara.

Revista de Educación y Desarrollo, 7. Octubre-diciembre. 17-25.

Recuperado de: http://www.cucs.udg.mx/revistas/edu desarrollo/anteriores/7/007_Nava.pdf; 
Ramírez, L. y Gallur, S. (2017). La perspectiva socio-cultural como modelo teórico de análisis de la reprobación académica en Educación Superior. Revista científico

Pedagógica Atenas, 2(38), 1-17.

Recuperado de:

https://www.aacademica.org/leticia.ra mirez/10.pdf

Reyes Seáñez, M.A. (2005). Una reflexión sobre la reprobación escolar en la educación superior como fenómeno social. Revista Iberoamericana de Educación, 39(7), 1-6. Recuperado de: http://rieoei.org/1510.htm

Ruiz, N., Romano, C., y Valenzuela, G. (2006). "Causas de reprobación vinculadas a las características de los estudiantes de la Licenciatura de Filosofía de la BUAP", Revista de la Facultad de Filosofía y Letras Graffylia, 4(6, 150-155). Recuperado de:

http://www.filosofia.buap.mx/Graffylia/ 6/150.pdf

Salas Martínez, Marco W. (2007) La evaluación del desempeño docente. Teoría e Investigación. U.V. Textos Universitarios.

SEP (2018) Principales Cifras del Sistema Educativo Nacional 20172018. Dirección General de Planeación, Programación y Estadística Educativa. México. Recuperado de:

https://www.planeacion.sep.gob.mx/D oclestadistica_e_indicadores/principa les_cifras/principales_cifras_2016_20 17.pdf
Silva B., Rodríguez A., Téllez R. y Leyva H. (2012). Opinión de los estudiantes acerca de los motivos de reprobación en las licenciaturas del centro universitario de ciencias económico-administrativas (CUCEA). Revista Pequén 2(1),185-204.

Recuperado de:

http://revistas.ubiobio.cl/index.php/RP /article/view/1840/1784

Talavera, R., Noreña, S., Melgar, A. y Plazola, S. (2006). Factores que afectan la reprobación en estudiantes de la Facultad de contaduría y Administración, UABC, Unidad Tijuana. Puebla, México: VI. Congreso Internacional Retos y Expectativas de la Universidad. 